\title{
An integrated assessment of climate change, air pollution, and energy security policy
}

\author{
Johannes Bollen ${ }^{\mathrm{a}}$, Sebastiaan Hers ${ }^{\mathrm{b}}$, Bob van der Zwaan ${ }^{\mathrm{c}, \mathrm{d}, *}$ \\ ${ }^{a}$ CPB Netherlands Bureau for Economic Policy Analysis, P.O. Box 80510, 2508 GM, The Hague, The Netherlands \\ ${ }^{\mathrm{b}}$ KYOS Energy Consulting, Nieuwe Gracht 49, 2011 ND, Haarlem, The Netherlands

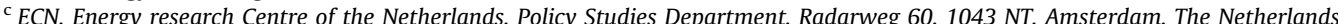 \\ ${ }^{\mathrm{d}}$ Columbia University, Lenfest Center for Sustainable Energy, Earth Institute, 500 West 120th Street, New York, NY 10027, USA
}

\section{A R T I C L E I N F O}

\section{Article history:}

Received 2 November 2009

Accepted 9 March 2010

Available online 27 March 2010

Keywords:

Climate change

Air pollution

Energy security

\begin{abstract}
A B S T R A C T
This article presents an integrated assessment of climate change, air pollution, and energy security policy. Basis of our analysis is the MERGE model, designed to study the interaction between the global economy, energy use, and the impacts of climate change. For our purposes we expanded MERGE with expressions that quantify damages incurred to regional economies as a result of air pollution and lack of energy security. One of the main findings of our cost-benefit analysis is that energy security policy alone does not decrease the use of oil: global oil consumption is only delayed by several decades and oil reserves are still practically depleted before the end of the 21st century. If, on the other hand, energy security policy is integrated with optimal climate change and air pollution policy, the world's oil reserves will not be depleted, at least not before our modeling horizon well into the 22nd century: total cumulative demand for oil decreases by about $24 \%$. More generally, we demonstrate that there are multiple other benefits of combining climate change, air pollution, and energy security policies and exploiting the possible synergies between them. These benefits can be large: for Europe the achievable $\mathrm{CO}_{2}$ emission abatement and oil consumption reduction levels are significantly deeper for integrated policy than when a strategy is adopted in which one of the three policies is omitted. Integrated optimal energy policy can reduce the number of premature deaths from air pollution by about 14,000 annually in Europe and over 3 million per year globally, by lowering the chronic exposure to ambient particulate matter. Only the optimal strategy combining the three types of energy policy can constrain the global average atmospheric temperature increase to a limit of $3{ }^{\circ} \mathrm{C}$ with respect to the pre-industrial level.
\end{abstract}

(c) 2010 Elsevier Ltd. All rights reserved.

\section{Introduction}

Today, energy policy is determined by essentially three types of arguments, related respectively, to (1) the global public bad of climate change, and regional negative externalities from (2) air pollution and (3) energy insecurity. Many studies have been performed that calculate the economic, environmental, and/or health damages resulting from especially (1) and (2), but so far it has proved difficult to quantify the impacts due to (3). Although energy security is recognized as an important issue, and has practically always been a fundamental determinant of national energy policies, it is not clear how damaging a lack of it may be to the economy. Much of the analytical work in this domain has recently focused on the design of indicators that allow for evaluating the level of energy insecurity: for some recent

\footnotetext{
* Corresponding author at: ECN, Energy research Centre of the Netherlands, Policy Studies Department, Radarweg 60, 1043 NT, Amsterdam, The Netherlands. Tel.: +31224564442.

E-mail address: vanderzwaan@ecn.nl (B. van der Zwaan).
}

proposals and overviews, see, for example, IEA (2007) and Jansen and Seebregts (2010). Instead of defining indicators that measure the size (or point towards the cause) of energy insecurity, we here seek to determine in quantitative terms the welfare losses as a result of energy insecurity and inspect the broader possible implications of the alleviation of energy resource concentration.

With the analysis described in this paper we try to reach two main goals. First, we attempt to quantify the concept of energy security, and add the resulting expression to an integrated assessment model simulating energy-economy-environment interactions. Second, we jointly analyze policies dedicated to, respectively, mitigating climate change, reducing air pollution, and enhancing energy security, in order to inspect whether their combined implementation can generate benefits that each individually cannot bring about.

Bollen et al. (2009) presented a combined cost-benefit analysis (CBA) of global climate change and local air pollution, two subjects that are usually studied separately. As explained in that study, these distinct environmental problems are closely related, since they are both driven by the nature of present energy 
production and consumption patterns. Their publication assessed how costs and benefits of technologies and strategies that jointly tackle these two environmental problems can best be balanced. The analysis demonstrated the mutual relevance of, and interaction between, policies designed to address these two environmental challenges individually. The main finding was that integrated environmental policies generate net global welfare benefits. The overall purpose of the present article is to investigate whether similar conclusions can be drawn when, in addition to global climate change management and local air pollution control, regional energy security measures are added to the CBA framework.

Section 2 of this article gives an overview of our adapted version of MERGE, and explains in detail how we extended the MERGE model further with a module covering energy security. We highlight our most important results in Section 3, in terms of simulated $\mathrm{CO}_{2}$ and particulate matter emission patterns and oil consumption reduction levels - for Europe and the world at large - as well as calculated environmental, health, and dependency benefits of policies dedicated to managing climate change, air pollution, and energy security. In Section 4 we briefly present our uncertainty analysis, while reserving Section 5 for our main conclusions and recommendations.

\section{The MERGE model}

Like in Bollen et al. (2009), for this study we use the well-established MERGE model (see Manne et al., 1995; Manne and Richels, 1995, 2004). MERGE allows for estimating in detail the costs and benefits of greenhouse gas (GHG) emission reduction policies, and is part of a large family of models designed for similar purposes (see, for example, Nordhaus, 1993; van der Zwaan et al., 2002; Gerlagh and van der Zwaan, 2004; Bosetti et al., 2009). In MERGE the domestic economy of each of its nine regions is simulated by a Ramsey-Solow model of optimal longterm economic growth, in which inter-temporal choices are made on the basis of a utility discount rate. Responses to price changes are introduced in an overall economy-wide production function. Output of the generic consumption good depends, like in other top-down or hybrid integrated assessment models, on the inputs of capital, labour, and energy.

One of the major causes of climate change are $\mathrm{CO}_{2}$ emissions, which originate from energy use simulated in MERGE in a bottom-up perspective. Separate technologies are defined for each main electric and non-electric energy option. In addition to $\mathrm{CO}_{2}$ emissions, MERGE includes relations that simulate energyrelated emissions of other GHGs, as well as non-energy-related GHGs. The GHGs emitted in each simulation period feed into the global atmospheric concentration of these gases. Every concentration increase matches a corresponding long-term global temperature increment.

We only use MERGE in its cost-benefit mode, in which it calculates an emission time path that optimizes welfare, that is, maximizes the sum of discounted utility of consumption. The production and consumption opportunities of the different regions are negatively affected by damages (or disutility) generated by global climate change (GCC). The scenarios analyzed with MERGE assume weak Pareto efficiency, that is, only states-of-the-world are considered in which no region can be made better off without making the other regions combined (essentially the world) worse off. Abatement of GHG emissions is optimally allocated with respect to the dimensions time (when), space (where), and type (what).

There is convergence between regions in terms of income per capita in our model runs, like in the original ones by Manne and
Richels $(1995,2004)$. GDP growth rates, determined by assumptions on population and productivity trends, are significantly higher for developing than for developed nations throughout the 21 st century, such that there is eventually full convergence (which does not materialize, however, before our time horizon of interest, i.e. 2100). Many other assumptions are of course determinant for the outcomes of MERGE model runs. Because MERGE has become such a well-established and commonly used tool for integrated assessment modeling of climate change, and has been used for so long already, its details have been extensively documented and archived. Hence we restrict ourselves here by referring to other publications for information on the remainder of these details (e.g. Manne et al., 1995; Manne and Richels, 1995, 2004).

\subsection{MERGE with air pollution}

For our prior publication we extended MERGE by including emissions of particulate matter (PM), which we assumed is the prime cause of damages induced by various sorts of local air pollution (LAP). We left the GCC part of MERGE unchanged with respect to its original form. We here briefly summarize our recent extensions, while referring to Bollen et al. (2009) for a description of the details. Having added the link between LAP and energy production, we obtained a model that simulates the costs and benefits from both GCC and LAP policies in a dynamic multiregional context. In our modified version of MERGE in each year and region an allocation of resources includes investments in endof-pipe PM abatement according to the relation:

$Y_{t, r}=C_{t, r}+I_{t, r}+J_{t, r}+K_{t, r}+D_{t, r}+X_{t, r}$

in which $Y$ represents output or GDP aggregated in a single good or numéraire, $C$ consumption of this good, $I$ the production reserved for new capital investments in the next time step, $J$ the costs of energy, $K$ the costs of PM abatement, $D$ the economic loss incurred by market-related damages from climate change, and $X$ the net export of the numéraire. ${ }^{1}$ Subscripts $t$ and $r$ refer to time and region, respectively. The complete set of tradables includes such products as oil, natural gas, and energy-intensive goods. Solving the cost-benefit problem implies reaching agreement on an international control system that leads to the temperature limit and avoided PM-related premature deaths that together minimize the discounted present value of the sum of abatement and damage costs. Disutility is associated with the damages resulting from GCC and LAP, as can be seen from the objective function (or maximand) of the total problem, i.e. the discounted sum of utility:

$\sum_{r} n_{r} \sum_{t} u_{t, r} \log \left(\eta_{t, r} \varphi_{t, r} C_{t, r}\right)$

with $n$ the Negishi weights, $u$ the utility discount factor, $\eta$ the disutility factor associated with monetised non-market damages resulting from GCC as percentage of consumption, and $\varphi$ similarly the disutility factor associated with LAP damages. ${ }^{2}$ As usual, utility is expressed as the logarithm of consumption. The loss factors $\eta$ and $\varphi$ reduce consumption $C$ through their multiplicative relationship: for example, if $\eta=0.90$ and $\varphi=0.95$ then $C$ is reduced by a factor $0.90 \times 0.95=0.855$ (hence by a little over $14 \%$ ). As in the original version of MERGE, the loss factor $\eta$ is

\footnotetext{
${ }^{1}$ Note that since $D$ represents market damages from GCC, it constitutes one of the competing claims on the allocation of total production, and hence appears in Eq. (1). Parallel to $K$ representing the costs of PM abatement, $J$ includes (in addition to the costs of conventional energy services and a large series of clean alternatives) the costs of $\mathrm{CO}_{2}$ abatement through CCS.

2 The impacts from LAP as introduced through $F$ include only non-market damages (i.e. health effects), since market damages are assumed to be negligible.
} 
expressed by

$\eta_{t, r}\left(\Delta T_{t}\right)=\left(1-\left(\Delta T_{t} / \Delta T_{c a t}\right)^{2}\right)^{h_{t, r}}$

in which $\Delta T$ is the global stabilized temperature rise with respect to its 2000 level, $h_{t, r}$ a time- and region-dependent 'hockey stick' parameter (assumed to be 1 for high-income regions and taking values below unity for low-income ones), and $\Delta T_{\text {cat }}$ the catastrophic temperature at which the entire world economic production would be annihilated. We deal with these quantities in the same way as in the original MERGE model, as described in Manne and Richels (2004). In short, $\Delta T$ is the optimal value of the average global temperature increase that we determine by running the model. The parameter $h$ is chosen such that for countries with per capita incomes higher than $\$ 50,000$, the willingness-to-pay to avoid a $2.5{ }^{\circ} \mathrm{C}$ temperature rise is $2 \%$ of GDP, while down to per capita incomes of $\$ 25,000$, the willingness-topay to avoid this temperature rise is 'only' $1 \%$ of GDP; $h$ is admittedly a highly speculative parameter, but the plausibility of the underlying principle is considered more relevant than the questionability of its numerical value. These assumptions imply a value for $\Delta T_{\text {cat }}$ of $18{ }^{\circ} \mathrm{C}$; the selection of this catastrophic temperature limit is also subject to sizeable uncertainty and may even be region-dependent, as confirmed in a concise recent overview in Rabl and van der Zwaan (2009). The newly introduced loss factor $\varphi$ takes the form

$\phi_{t, r}=1-\frac{1.06 N_{t, r}}{C_{t, r}}\left(\frac{Y_{t, r} / P_{t, r}}{Y_{2000, \text { weur }} / P_{2000, \text { weur }}}\right)$

in which $N$ is the number of premature deaths from chronic exposure to $\mathrm{PM}$, and $P$ the exogenous number of people in a given population. The loss factor $\varphi$ in this version of MERGE includes detailed account of (i) the relation between PM emissions and ambient PM concentrations, (ii) the link between increased PM concentrations and incurred premature deaths, and (iii) the meaning of these deaths in terms of their monetary value. The variable $N$ results from steps (i) to (ii), while the factor 1.06 in Eq. (4) establishes the link to (iii) given our assumption that the value-of-statistical-life (VSL) for the base year 2000 in Europe equals approximately 1.06 million US\$(2000). For non-European regions, the VSL is determined by multiplying the VSL of OECD Europe (our reference region, indicated by subscript weur in Eq. (4)) with the ratio of GDP per capita of these respective regions. For future years the VSL is assumed to rise according to the growth rate of GDP per capita (see also Viscusi and Aldy, 2003). For several pages of text explaining the derivation of Eq. (4), including a detailed specification of our assumptions regarding dose-response functions, we refer to our recent publication (Bollen et al., 2009). As we pointed out there we much agree with the recommendation by Holland et al. (2004) to use both the VSL and value-of-a-life-year-lost (VOLY) methods to value mortality incurred from PM exposure. We justified in that article our choice for taking the median estimate of the VSL approach in 2000 as our benchmark case.

The damages resulting from GCC can be avoided by deploying energy (electric and non-electric) technologies that involve low or zero levels of GHG emissions. The damages resulting from LAP can be avoided by end-of-pipe measures, in which traditional energy technologies are complemented with additional devices that capture PM. The expanded version of MERGE includes marginal cost abatement curves not only for GHG emissions (most importantly $\mathrm{CO}_{2}$ ) but also for emissions of PM. Mitigation means can address either GCC or LAP, or alternatively both at once. Energy savings for example, one of the means to mitigate climate change, simultaneously reduce the intensity of PM. For further reading on our modeling assumptions we refer to Bollen et al. (2009).

\subsection{MERGE with energy security}

For our present study we have expanded MERGE with an expression that quantifies damages due to a lack of energy-related security of supply (SOS). For this purpose we have replaced Eq. (2) by

$\sum_{r} n_{r} \sum_{t} u_{t, r} \log \left(\eta_{t, r} \phi_{t, r} \sigma_{t, r} C_{t, r}\right)$

in which the extra factor $\sigma$ is added to account for disutility associated with an insufficient energy-related SOS. Similarly as with the factors $\eta$ and $\varphi$, the loss factor $\sigma$ reduces consumption by being multiplied with $C$, and is determined by

$\sigma_{t, r}=1-\sum_{f \in\{\text { oil,gas }\}} \Omega_{f, t, r}$

in which $\Omega$ is the penalty function, for either oil or natural gas as indicated by the subscript $f$, expressing the willingness-to-pay to avoid a lack of SOS in percentage terms of generic consumption. A low SOS value for oil or natural gas translates into a high value for $\Omega$. As can be seen from relation (6), a high value of $\Omega$ induces a low value of $\sigma$. The lower the value of $\sigma$, the more significant the negative effect on overall utility (Eq. (5)). While Eq. (6) quantifies the relative welfare loss associated with security of supply risks, Eq. (5) includes this welfare loss in the objective function of MERGE. The region- and time-dependent loss factor $\sigma$ aggregates the consumption losses of oil- and gas-related SOS deficiencies through the penalty function $\Omega$. The latter is calculated for each fuel type by

$\Omega_{t, r}=\theta_{r}\left(\frac{i_{t, r}}{i_{0, r}}\right)^{\alpha}\left(\frac{c_{t, r}}{c_{0, r}}\right)^{\beta}\left(\frac{e_{t, r}}{e_{0, r}}\right)^{\gamma}$

in which $\theta$ is an overall region-dependent scaling factor, $i$ the import ratio, $c$ the consumption ratio, and $e$ the energy intensity. The exponents $\alpha, \beta$, and $\gamma$ allow for flexible assumptions regarding the nature of the dependency of $\Omega$ on these three variables. The ratio $i$ is defined as the imported amount of fuel divided by the total demand for that fuel by the region under consideration. ${ }^{3}$ The quantity $c$ is the consumption level of the energy commodity divided by the consumption of energy at large. The intensity factor $e$ is the consumption of energy per unit of GDP. If a country is not dependent on foreign energy imports but instead exports energy (so that $i<0$ ), then $\Omega$ equals zero. For modeling purposes, we express variables $i, c$, and $e$ with respect to their normalised values at $t=0$.

This penalty function expresses that there is willingness-topay to address a lack in SOS, when (1) there is more commodity import dependency, (2) there is higher commodity dependency, or (3) the economy is more dependent on energy services. We propose a multiplicative structure because each of the contributing factors is expected to affect the level of impact of the other factors. For example, import dependency becomes more critical if the relative commodity dependency or relative energy dependency increases, and vice-versa. We assume that the damage function of Eq. (6) is convex with respect to each of its three factors, that is, the relative impact of changes in the individual factors becomes larger if the factors themselves become larger. For instance, the first percent of import dependency will be less critical in terms of SOS-related welfare losses than the last percentage. The values for $\alpha, \beta$, and $\gamma$ are thus assumed to be larger than 1 . In our central case we have supposed relatively conservative values of $1.1,1.2$, and 1.3 , respectively - in ascending

${ }^{3}$ In practice this $i$-ratio is only active for natural gas, since we assume that the price heterogeneity of oil is much smaller so that it becomes less relevant whether the oil is imported or produced domestically. 
order, as argued in Bollen (2007), in order to maintain convexity in each of the arguments. In our sensitivity analysis, we also experiment with significantly higher values, exceeding 2 (but remaining lower than 3). Quadratic rather than cubic exponents for this penalty function are much in line with the growing body of literature in which the exponent of the climate damage function (Eq. (3)) is for practical reasons assumed to take a value around 2 (for recent expositions on this figure see, for example, Heal, 2009; Rabl and van der Zwaan, 2009). In our base case, the scaling factor $\theta$ is set at 0.005 . This value reflects that, for example, France has been willing to pay some $0.5 \%$ of private consumption levels during the 1970s for the phase-out of oil-fired power plants in favour of nuclear energy, basically in order to ascertain a higher level of energy security. We are aware that also the value assumed for $\theta$ is rather speculative, which is why we conduct an uncertainty analysis to test the robustness of our main results.

Policies that successfully reduce exposure to energy system perturbations generally involve diversification, typically at increasing costs. Three types of diversification strategies can be identified, regarding (1) the supply portfolio of a given energy commodity (implying a reduction of import dependency), (2) the energy portfolio (implying a reduction of oil and/or gas dependency), and (3) the production factors (implying a reduction of energy dependency). These three dimensions of diversification are reflected in Eq. (7). Diversification in terms of the supply portfolio of a given commodity may also involve an increase in the number of suppliers, or shifts from high-risk to low-risk suppliers, but these phenomena are not represented in our adapted version of MERGE. As with other MERGE simulations, our analysis is restricted to full market competitiveness assumptions, also in relation to the availability and price of fossil fuels.

The inclusion of Eq. (7) in a model like MERGE is a world premier in the sense that ours is the first attempt to include energy security as additional argument in an integrated assessment model simulating energy-economy-environment interactions. Certainly much more work can (and should) be done in the future to refine our first rudimentary approach, and it goes without saying that especially more efforts are needed to back the empirical basis of Eq. (7). As extensively described in Bollen (2007), we calibrated this penalty function by relying on a couple of historical examples of national policies which sought to reduce long-term energy supply risks. On the basis of such political decisions and the associated investments realized, approximations can be made for the willingness-to-pay to enhance security of energy supply, which in turn help determining the parameters of Eq. (7). Several instances in the past confirm that the willingness-to-pay for large national projects dedicated essentially to ensure energy supply security (such as in Brazil, France, the Netherlands and in the US) amounted to up to $1 \%$ of private consumption opportunities. For more details on Eq. (7) and the specific modeling of SOS, we refer to Bollen (2007).

\section{Results}

We perform our study by running the adapted MERGE model for a set of different energy policy scenarios. We focus on the countries in Europe that are member of the Organisation for Economic Co-operation and Development (OECD) as our main region of interest, but inspect several policy-relevant issues on the global level as well.

\subsection{Scenarios}

To analyze the respective effects of GCC, LAP, and SOS policy, we define eight scenarios. These scenarios, as specified in Table 1 ,
Table 1

Eight scenarios for the integrated assessment of GCC, LAP, and SOS policy.

\begin{tabular}{llll}
\hline Scenario & Policy & & \\
\cline { 2 - 4 } & GCC & LAP & SOS \\
\hline BAU & & & \\
GCC & $\mathrm{x}$ & & \\
LAP & & $\mathrm{x}$ & $\mathrm{x}$ \\
SOS & $\mathrm{x}$ & $\mathrm{x}$ & $\mathrm{x}$ \\
GAP & $\mathrm{x}$ & $\mathrm{x}$ & $\mathrm{x}$ \\
GOS & & $\mathrm{x}$ & $\mathrm{x}$ \\
LOS & $\mathrm{x}$ & & \\
GLS & & & \\
\hline
\end{tabular}

distinguish themselves by the presence or absence of measures fit to address one or more of these three main concerns related to the energy sector. They are modeled by switching on or off the loss factors $\eta, \varphi$, and $\sigma$ in the objective function of MERGE, either alone or in combination. These factors are turned off by setting them exogenously equal to 1 , and are rendered active by allowing their endogenous determination through model runs. In the latter case they obtain values $<1$, so that overall consumer utility decreases. For example, in the business-as-usual (BAU) scenario (no policy whatsoever) all three factors are set to 1 , while in scenario GLS (all policies are implemented) each of them is operational and thus $<1$. The scenarios listed in Table 1 represent the complete combinatorics of possibilities.

Implementing policy to manage GCC, LAP, and SOS - that is, in modeling terms, activating the loss factors $\eta, \varphi$, and $\sigma$ - implies the internalization of the damages (negative externalities) induced by climate change, air pollution, and insecurity of supply, respectively. In other words, in the different policy cases the external costs or dual (shadow) prices of environmental preservation (regarding the atmosphere or air) or energy security are included in the prices of energy services and hence consumer goods.

\subsection{Results for OECD Europe}

We investigate first the particular case of modeling results for OECD Europe because data on the costs of climate change, air pollution, and energy insecurity, as well as the costs of the means to avoid or mitigate these concerns, prove most abundant and refined for this region. European data thus allow calibrating most accurately the corresponding penalty functions, in comparison to data from other regions, which are sometimes unknown or poorly reported. As explained in Bollen (2007) and Bollen et al. (2009), the penalty functions for other regions are derived from those assumed for OECD Europe, which functions as our model's reference.

Fig. 1 shows for OECD Europe the emissions of $\mathrm{CO}_{2}$ throughout the century for each of our eight scenarios. There is understandably clear distinction between the four scenarios in which no climate policy is adopted versus those in which stringent climate control is achieved. We see that if climate policy is combined with either air pollution or energy security policy, then additional reductions of $\mathrm{CO}_{2}$ emissions are realized. If climate policy is complemented with both these other policies, then the climate bonus is most significant. Europe's emissions of $\mathrm{CO}_{2}$ fall below a level of $0.3 \mathrm{GtC} / \mathrm{yr}$ in 2100 in an optimal strategic contribution to global climate mitigation efforts. It can also be observed that if only energy security policy is implemented, $\mathrm{CO}_{2}$ emissions increase with respect to BAU, the explanation for which is that a share of oil and natural gas usage is replaced by carbonintensive coal-based power technologies. For air pollution policy 


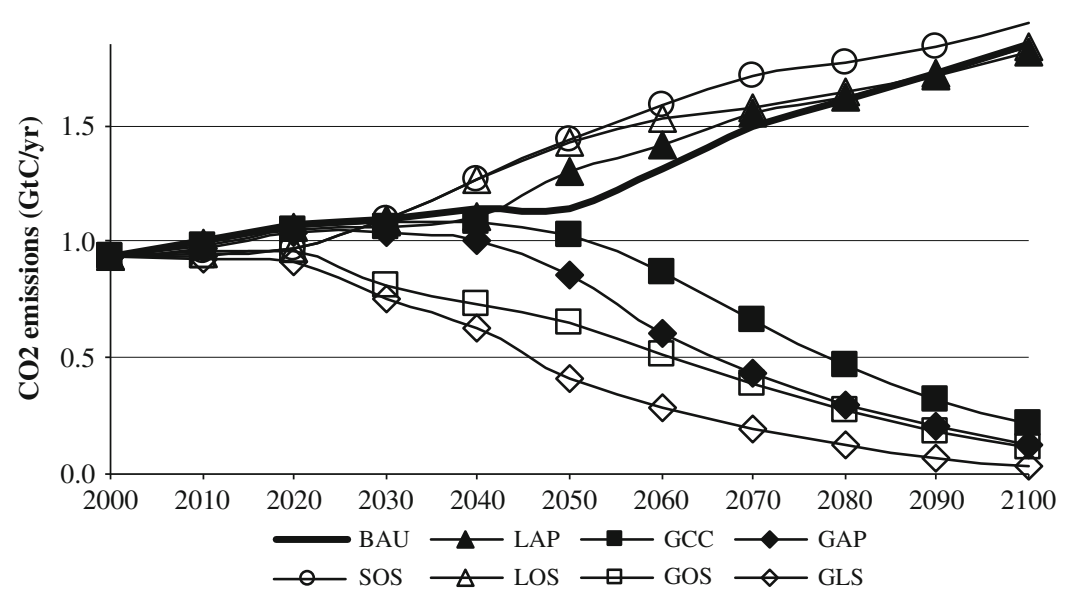

Fig. 1. $\mathrm{CO}_{2}$ emissions $(\mathrm{GtC} / \mathrm{yr})$ from $\mathrm{OECD}$ Europe in our eight policy scenarios.

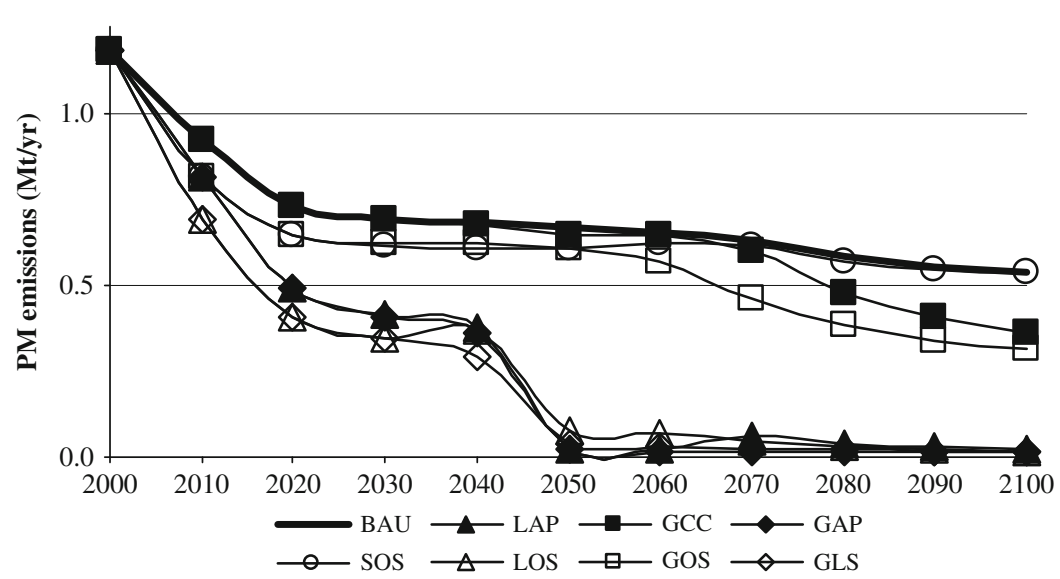

Fig. 2. PM emissions (Mt/yr) from OECD Europe in our eight policy scenarios.

during several decades a similar phenomenon applies, as a result of some oil and natural gas consumption being substituted by coal-based power complemented with PM abatement technology.

Fig. 2 shows for OECD Europe the emissions of PM throughout the century for each of the eight scenarios. Two categories of policy scenarios can be distinguished: one that includes air pollution control and another one without such policy, with an obvious difference in the PM emission reductions achieved. In Europe optimal air pollution policy would reduce emissions of PM to levels of essentially zero in 2100 , while without such policy by the end of the century still about $0.5 \mathrm{Mt}$ of PM is emitted annually into the ambient air. Interestingly, if no air pollution policy is adopted but climate policy instead (either or not in combination with energy security policy), then an air pollution bonus is obtained that amounts to a PM emission reduction of some $0.2 \mathrm{Mt}$ annually around $2100 .^{4}$

In Fig. 3 the European consumption evolution of oil is depicted until 2100 for each of the eight scenarios. Until about the middle of the century a clear difference can be observed between the scenarios without energy security policy, on the one hand, and those that internalize such policy, on the other hand. After a steep reduction in the first decade from close to $30 \mathrm{EJ} / \mathrm{yr}$, during about four decades oil imports remain stable down at around $20 \mathrm{EJ} / \mathrm{yr}$ in case energy security policy is implemented. From about 2050,

\footnotetext{
${ }^{4}$ In scenario GCC this results mostly from a phase out of the use of coal outside the power sector, while in scenario GOS also the use of oil is reduced (with respect to $\mathrm{BAU})$.
}

however, oil consumption starts to decline rapidly in all eight scenarios. From then onwards there is increasing convergence between all scenarios in terms of the level of total European oil consumption. The reason is that by the end of the century global oil reserves are either nearly depleted or are left unused for environmental reasons. We observe that during the second half of the century there is little difference between the level of European oil consumption in the energy security policy case vis-á-vis that in the BAU scenario. It proves that when climate change, air pollution, and energy security policy are integrated, the delay in cumulative demand for oil is most significant. In that case, oil consumption levels in 2100 in Europe amount to about $10 \%$ of what they are today.

\subsection{Global results}

Two of the three analyzed concerns have direct repercussions on both the regional and global level. The challenge of GCC is of course global in nature and determined by the total level of GHG emissions of all regions combined, while the expected depletion of oil reserves during the 21st century on a world scale affects SOS in essentially all regions given their current high dependency on this fossil fuel. We therefore also present our modeling results as applied to the sum of all regions simulated. LAP is mostly a problem of regional (or national) importance only. Yet policy designed to address LAP at the regional level may have an indirect impact on the global level, since the favoring or discrediting of 


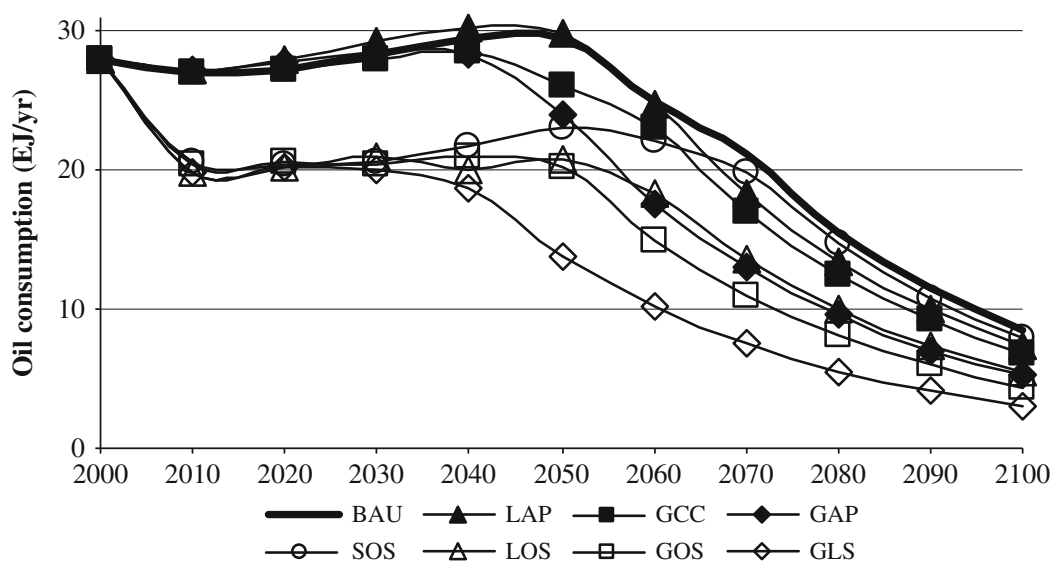

Fig. 3. Oil consumption (EJ/yr) in OECD Europe in our eight policy scenarios.

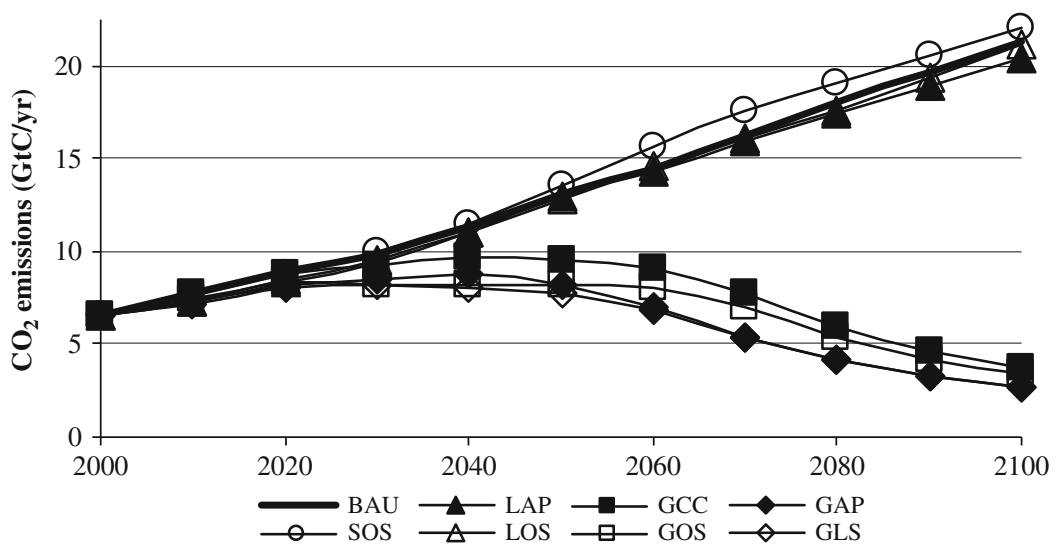

Fig. 4. Global $\mathrm{CO}_{2}$ emissions $(\mathrm{GtC} / \mathrm{yr})$ in our eight policy scenarios.

certain energy technologies by LAP measures in one given region may spill over to other regions.

Fig. 4 shows the global emissions of $\mathrm{CO}_{2}$ during the century for each of the eight scenarios. As in Fig. 1, there is a clear grouping between the four no-climate-policy scenarios and the four climate control ones. European $\mathrm{CO}_{2}$ emissions account today for about $16 \%$ of the global figure, while in 2100 they have fallen well below $10 \%$ of the world level, for both of these two scenario categories, due to the increasing contribution to global emissions from the developing world. We see again that if climate policy is combined with air pollution and/or energy security policy, additional reductions of $\mathrm{CO}_{2}$ emissions are realized, thus implying an extra climate management gain. Global emissions of $\mathrm{CO}_{2}$ fall to a level of about $3-4 \mathrm{GtC} / \mathrm{yr}$ in 2100 in an optimal strategic climate mitigation program. Such still relatively modest $\mathrm{CO}_{2}$ reduction levels are insufficiently deep to constrain the increase of atmospheric $\mathrm{CO}_{2}$ concentration within an upper limit of $560 \mathrm{ppm}$ (i.e. a doubling with respect to the pre-industrial level).

Fig. 5 shows the trajectory of the global PM emission level for each of the eight scenarios. As in Fig. 2, we can clearly distinguish two different groups of policy scenarios: one that includes air pollution control and another without such intervention, with an obvious difference in the PM emission reduction level achieved. Unsurprisingly, also for the world as a whole the optimal air pollution strategy would reduce PM emissions down to essentially zero in 2100 , while without any such environmentalcum-health policy by the end of the century still about $10 \mathrm{Mt}$ of PM would be emitted annually. If no air pollution is adopted but climate policy instead (either or not in combination with energy security policy), also an ambient air quality improvement is obtained, amounting to a PM emission reduction of some $5 \mathrm{Mt}$ annually in 2100 . This is a $50 \%$ reduction with respect to the BAU reference case.

Fig. 6 plots the evolution of global oil consumption until 2100 for each of our scenarios. Until about the middle of the century there is a fair difference between the scenarios without energy security policy, respectively, those that include such policy. During about the first four decades oil consumption is significantly reduced in the latter ones, but for a couple of these scenarios this reduction is only temporary and involves no more than a delay in its use: oil consumption picks up again during the second half of the century. By the end of the century in all scenarios global oil consumption declines, but there is significantly less convergence between the scenarios in comparison to the European case. There is only one scenario in which there is both a significant reduction in cumulative oil demand during the first half of the century and a steep decline in oil consumption during the second half of it: the case in which climate change, air pollution, and energy security policy are combined. In this scenario there is significant delay in the cumulative demand for oil, to such an extent that until the modeling horizon of 2150 oil will not be entirely depleted - in the other scenarios global oil reserves have all essentially been exploited. Cumulative demand for oil in the all-policy scenario is lower by about $24 \%$ in comparison to that in the other scenarios. 


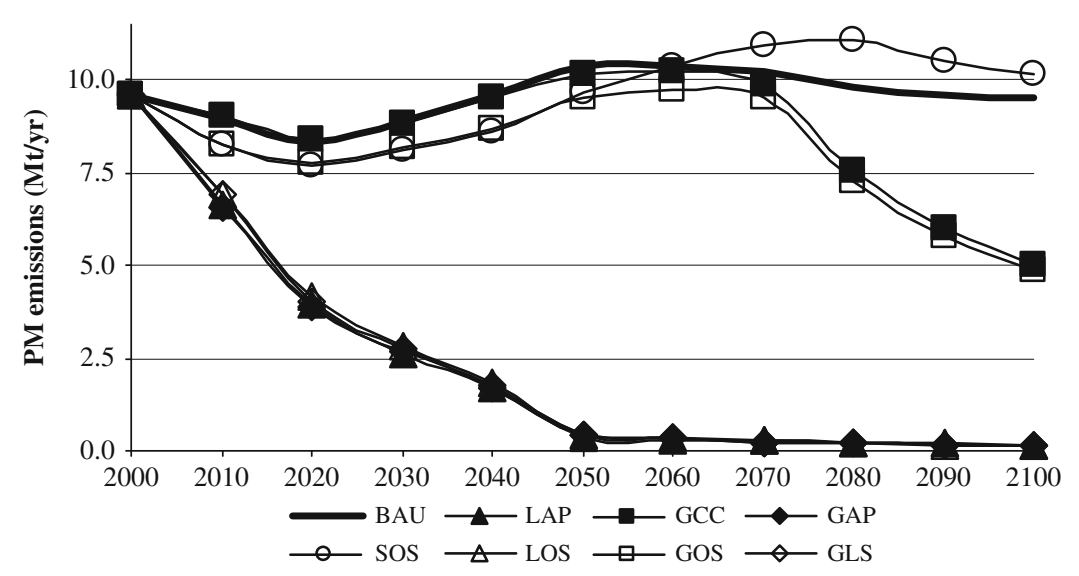

Fig. 5. Global PM emissions (Mt/yr) in our eight policy scenarios.

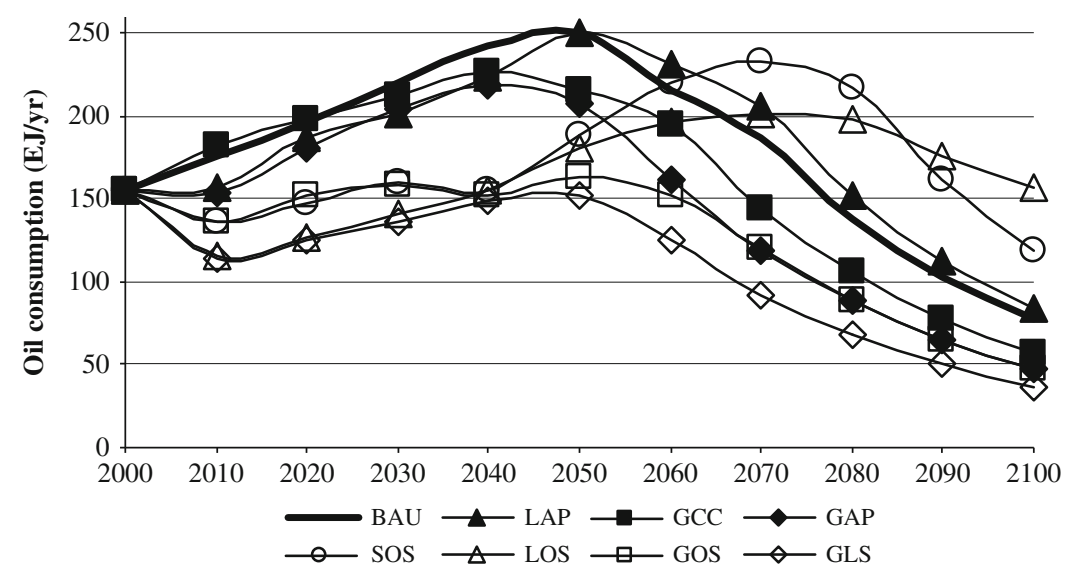

Fig. 6. Global oil consumption (EJ/yr) in our eight policy scenarios.

Table 2

Global temperature increase in $2150\left({ }^{\circ} \mathrm{C}\right.$, relative to the pre-industrial level) in our policy scenarios.

\begin{tabular}{lllllllll}
\hline$\Delta T\left({ }^{\mathbf{0}} \mathbf{C}\right)$ & BAU & LAP & GCC & GAP & SOS & LOS & GOS & GLS \\
\hline & 4.9 & 4.8 & 3.2 & 3.0 & 5.0 & 4.9 & 3.1 & 3.0 \\
\hline
\end{tabular}

\subsection{Environmental, health, and dependency benefits}

The differences in climate benefits between the eight policy scenarios are large. Table 2 shows that in 2150 in the BAU scenario the global temperature increase compared to the preindustrial average atmospheric temperature amounts to $4.9{ }^{\circ} \mathrm{C}$. Applying climate policy reduces this level considerably, down to $3.2^{\circ} \mathrm{C}$, while air pollution or energy security policy hardly affects this elevated temperature level. If climate policy is complemented with air pollution policy, an extra climate bonus is obtained that amounts to a further decrease of another approximately $0.2^{\circ} \mathrm{C}$. If all three types of energy policies are integrated, we observe that the optimal global temperature increase amounts to $3.0^{\circ} \mathrm{C}$, that is, still $1.0^{\circ} \mathrm{C}$ higher than the strategic value of $2.0^{\circ} \mathrm{C}$ adopted by the EU (2007). The latter is seen as the value beyond which climate change is considered dangerous.

Table 3 shows that the introduction of optimal air pollution can reduce the cumulative number of premature deaths over the period 2000-2050 by about 160 million worldwide and by over 0.6 million in OECD Europe. In other words, on the global level yearly on average over 3 million premature deaths can be avoided
Table 3

Cumulative premature deaths (millions, 2000-2050) in our policy scenarios.

\begin{tabular}{lcccccccc}
\hline$\sum N\left(\mathbf{1 0}^{\mathbf{6}}\right)$ & BAU & LAP & GCC & GAP & SOS & LOS & GOS & GLS \\
\hline World & 222 & 62 & 220 & 62 & 192 & 68 & 194 & 67 \\
Europe & 1.8 & 1.2 & 1.7 & 1.2 & 1.6 & 1.1 & 1.6 & 1.1 \\
\hline
\end{tabular}

through the implementation of optimal air pollution reduction measures. This is the same order of magnitude as the number of casualties annually from HIV/AIDS and malaria combined (WHO, 2004). ${ }^{5}$ In relative terms the effect of air pollution control is more significant globally (a 72\% reduction) than on the European level (31\%). The explanation is that in Europe much of the achievable PM abatement technologies have already been implemented, while especially in the developing world, notably China and India, most of these reductions are still to be realized. Interestingly, climate and energy security policies also bring about some benefits in terms of reducing PM-induced premature deaths. In the case of OECD Europe, a combination of all three energy policies achieves the most drastic premature deaths reduction (40\%), corresponding on average to a reduction of some 14,000 premature deaths annually.

\footnotetext{
${ }^{5}$ Note, however, that the number of life years lost for HIV/AIDS and malaria is probably on average some three to four times higher than in the case of premature deaths resulting from air pollution.
} 
Table 4

European security loss (\%, oil, natural gas and total) in our policy scenarios.

\begin{tabular}{lllllllll}
\hline $\boldsymbol{\Omega}(\%)$ & BAU & LAP & GCC & GAP & SOS & LOS & GOS & GLS \\
\hline Oil 2050 & 0.2 & 0.3 & 0.2 & 0.2 & 0.1 & 0.1 & 0.1 & 0.0 \\
Gas 2050 & 1.7 & 0.5 & 1.5 & 0.9 & 0.0 & 0.0 & 0.0 & 0.0 \\
Total 2050 & 2.0 & 0.7 & 1.6 & 1.0 & 0.1 & 0.1 & 0.1 & 0.0 \\
\hline
\end{tabular}

N.B.: For both oil and natural gas $\Omega$ in 2000 is assumed to be 0.5 (and for their sum 1.0).

Table 4 lists the penalty function $(\Omega)$ values for oil, natural gas, and their sum, for OECD Europe, both for the base year and 2050. As argued in Bollen (2007), we assume for the year 2000 a value for the sum of $\Omega_{\text {oil }}$ and $\Omega_{\text {gas }}$ equal to $1 \%$ of total consumption of the numéraire, evenly split between these two penalties. In the nopolicy BAU scenario this level increases to $2 \%$ in 2050 because of a rapidly increasing dependency on imports of natural gas during the forthcoming decades, mostly from Russia, while the oil dependency slightly decreases over the same period. We see that if energy security policy is introduced the dependency on both oil and natural gas is drastically reduced, resulting in a value for $\Omega_{t o t}$ of 0.1 or lower in 2050 . This reflects that under the new circumstances induced by the imposed energy security policy, the willingness-to-pay to decrease the remaining part of fossil fuel dependency has been substantially reduced with respect to the situation in 2000. As can also be seen from Table 4, air pollution policy introduces an increase of energy security in 2050 in Europe, while climate policy reduces this security. The reason for the former is that air pollution policy stimulates coal-based power technology equipped with PM capture techniques, and this clean use of coal can replace part of the oil imports. The explanation for the latter is that climate policy induces, apart from the diffusion of CCS technology, shifts away from carbon-intensive coal and oil to natural gas based electricity generation, thereby increasing the reliance on foreign imports of this carbon-extensive gas.

\section{Uncertainty analysis}

MERGE can only calculate optimal time-dependent pathways for $\mathrm{CO}_{2}$ and PM emissions, as well as for levels of oil consumption, under specific assumptions for their impacts. In its cost-benefit mode MERGE generates monetary values for the total benefits of realized climate change mitigation, air pollution reduction, and security of supply control, the results of which are dependent on these assumptions. In our previous publication (Bollen et al., 2009) we presented the findings of a detailed uncertainty analysis for the most relevant of these assumptions, in terms of globally aggregated discounted costs and benefits of implemented GCC and LAP policies. We calculated how the costs and benefits (expressed as percentages of total discounted consumption in the BAU scenario) of these policies changed for varying parameter assumptions.

Our conclusions were that while different parameter assumptions may sometimes generate significantly different modeling outcomes, the main conclusions as reported in Bollen et al. (2009) were robust under different values for these parameters. In particular, we tested varying assumptions regarding (1) the PM emission level of developing regions, (2) the urbanization level of these regions, (3) the relationship between PM emissions and PM concentrations, (4) the value of the climate sensitivity, (5) the value of a statistical life (VSL), (6) the value of the discount rate (descriptive or prescriptive), (7) the relationship between VSL and GDP and whether the latter is expressed in market exchange rates or purchasing power parity, and (8) the level of damages due to climate change. We refer to this prior article for a more detailed clarification of these sensitivity variations.

Bollen (2007) reports an extension of this sensitivity study, by also investigating variations of assumptions with regards to (9) the convexity of the SOS penalty function, (10) the overall level of damages as determined by the SOS penalty function, (11) the relationship between the value of SOS impacts, the energy intensity of a region, and whether in the latter GDP is expressed in market exchange rates or purchasing power parity, and (12) other forms of discounting, including discounting according to Weitzman (2001). In Bollen (2007) it is extensively described how these varying assumptions affect our modeling outcomes in terms of global cumulative demand for oil and natural gas, and the $\mathrm{CO}_{2}$ reduction level in 2025 in OECD Europe, under a combination of GCC, LAP, and SOS policies. We here give a summarized account of the main sensitivity findings reported in that publication and focus on the subject of energy security of supply, the main new element in our expanded version of MERGE.

One of our main findings is that when energy security concerns are left out of integrated policy addressing climate change, air pollution, and energy security - in other words, when we compare our GLS versus the GAP scenario - then the global cumulative demand for oil (integrated over the period 2000-2150) is reduced by approximately $24 \%$ (which we refer to as our central case). Table 5 lists values for the same variable, hence under a comparison of the same two scenarios, but with varying assumptions regarding the shape, scale and use of the penalty function $\Omega$. In our central case, the exponents $\alpha, \beta$, and $\gamma$ in Eq. (7) are fixed rather randomly (at 1.1, 1.2 , and 1.3 , respectively), mostly by lack of information on their precise value. We have argued reasons for assuming that these parameters are $>1$, but that still leaves a wide range of choices open. In our sensitivity exercise we changed the convexity of the penalty function by increasing these exponents up to $1.5,2.0$, and 2.5 , respectively. As can be seen from Table 5, the effect on the global consumption of oil is limited: the central figure of $-24 \%$ turns into $-20 \%$. The stronger convexity of the penalty function yields a significant further reduction of oil consumption (and likewise of natural gas demand) during the first decades of our simulation. In the long term, however, oil usage picks up as a result of our choice that the third factor in Eq. (7) is significantly more convex (an exponent of 2.5) than the first two factors (exponents of 1.5 and 2.0). This explains why Table 5 lists more cumulative oil demand in the second column (higher convexity test) than in the first (central case).

Another essential parameter in Eq. (7) is the scaling factor $\theta$, which determines the overall level of costs incurred as a result of a lack of energy security. By increasing its central value (calibrated to reflect a number of historical examples) by a factor of 3 , or similarly reducing it by this factor, we cover a wide range of assumptions regarding the willingness-to-pay to increase energy security of supply. Table 5 shows that these scaling changes have quite an impact on our modeling result for global oil demand, but the thrust of its meaning remains unmodified. The energy intensity $e$ in Eq. (7) is calculated with respect to GDP. The latter is in our central case expressed in market exchange rates, or MER. We see from Table 5 that the replacement of MER by purchase power parity, or PPP, has no discernable effect in terms of our finding for the global demand for oil. We have also performed a test regarding the applicability of $\Omega$. Suppose only the EU implements policy that internalizes external effects as a result of a lack of security of energy supply. What then would be the impact on its and the rest of the world's demand for oil? The EU itself would of course drastically decrease its oil consumption, but, as Table 5 shows, if other regions do not follow implementing similar energy security policy, global oil reserves will essentially be depleted before the middle of the 22nd century. 
Table 5

Global cumulative demand for oil (2000-2150) in the GLS versus the GAP scenario under different assumptions for the penalty function $\Omega$.

\begin{tabular}{|c|c|c|c|c|c|}
\hline Central & $\begin{array}{l}\text { Convexity } \\
\alpha, \beta, \gamma\end{array}$ & $\begin{array}{l}\text { Scaling } \\
\theta \times 3\end{array}$ & $\begin{array}{l}\text { Scaling } \\
\theta / 3\end{array}$ & $\begin{array}{l}\text { MER-PPP } \\
\text { GDP in } e\end{array}$ & $\begin{array}{l}\text { Except EU } \\
\Omega_{r}=0\end{array}$ \\
\hline$-24 \%$ & $-20 \%$ & $-38 \%$ & $-10 \%$ & $-24 \%$ & $-3 \%$ \\
\hline
\end{tabular}

The conclusion also for this additional sensitivity study is thus that different parameter assumptions may induce substantially altered simulation outcomes. The main conclusions, however, as reported in the present article, regarding the depletion of global reserves of oil and natural gas and the synergies realizable between different types of energy policy in an integrated strategy, prove robust under these varying assumptions.

\section{Conclusions and recommendations}

Since the seminal work by Nordhaus (1977, 1993), studying the economics of climate change through integrated assessment models has become a large sub-discipline. The Stern Review has brought the subject of climate change under the attention of a wide audience and has reshaped the thinking about the economic aspects of this global challenge (Stern, 2006). Among the flow of literature created following the publication of the Stern Review, Heal (2009) in particular points towards the topics that still need to be much better understood. We agree with his assessment that, among the many issues that ought to be further researched, especially the uncertainties associated with climate change impacts and the damages caused to environmental goods need to be much better understood (see also Gerlagh and van der Zwaan, 2002). Uncertainty is probably the main thrust of future research in the field of climate change economics. We simultaneously, however, feel uncomfortable with the fact that the focus of this stream of studies remains in essence on climate change only. The transformation of our energy system is at the core of solutions to global warming, but concerns over air pollution and energy security are equally important arguments that define how this transition will take place. This article is a first effort to compensate for the current corresponding hiatus in the literature, and attempts to draw these two additional themes into the sphere of integrated assessment modeling.

In our previous paper we demonstrated that the discounted benefits of local air pollution reduction significantly outweigh those of global climate change mitigation, at least by a factor of 2 , but in most cases of our sensitivity analysis much more (Bollen et al., 2009). We explained, however, that we hereby did not want to argue to only restrict energy policy today to what should be our first priority, local air pollution control, and wait with the reduction of greenhouse gas emissions. Instead, we concluded that policies simultaneously addressing these issues create an additional climate change bonus. As such, climate change mitigation proves an ancillary benefit of air pollution reduction, rather than the other way around. With the simulation results presented in this paper we expand these conclusions on the basis of policies that integrate concerns of not only climate change and air pollution, but also energy security.

The multi-regional MERGE model was originally designed to study the interaction between the global economy, energy use, and the impacts of climate change. For our purposes we expanded MERGE with expressions that quantify damages incurred to regional economies as a result of air pollution (Bollen et al., 2009) and lack of energy security (the present paper). One of our main new findings is that energy security policy alone does not decrease the use of oil: global oil consumption is only delayed by several decades. It will nevertheless be almost totally depleted before the end of the 21st century. If, on the other hand, energy security policy is combined with optimal climate change and air pollution policy, the world's reserves of oil will not be entirely depleted, at least not before our modeling horizon of 2150. In that case, cumulative demand for oil decreases by about $24 \%$ in comparison to the other cases we analyzed.

We also demonstrated that there are multiple other benefits of combining climate change, air pollution, and energy security policies, and exploiting the possible synergies between them, and that the corresponding gains can be large. The combination of climate change, air pollution, and energy security policies, adopted by all regions, results in regions heavily dependent on foreign oil and natural gas to reduce their imports, and correspondingly regions producing oil and natural gas to reduce their exports and increase their domestic consumption of these fossil fuels. Consequently, oil exporters increase their emissions of $\mathrm{CO}_{2}$, but these increases are largely out-shadowed by the emission reductions achieved by the traditional oil importers. Given the triplet of these policies, especially Europe proves to start reducing its $\mathrm{CO}_{2}$ emissions significantly already between 2020 and 2030. For Europe the achievable $\mathrm{CO}_{2}$ emission abatement and oil consumption reduction levels are significantly deeper for integrated policy than when a strategy is adopted in which one of the three policies is omitted. Integrated optimal energy policy can reduce the number of premature deaths from the chronic exposure to air pollution by 14,000 annually in Europe and over 3 million per year globally, by reducing exposure to elevated ambient PM concentrations. Only the combination of the three types of energy policy that we inspect can constrain the global average atmospheric temperature increase to a limit of $3{ }^{\circ} \mathrm{C}$ with respect to the pre-industrial level.

These results are of course subject to the novelty of our approach and the uncertainties present in many of our modeling parameters. We consider the above therefore not as the achievement of a final set of findings, but as the start of a new method of search and research. Certainly many of our assumptions can be subjected to further and extensive uncertainty analysis, and the sensitivity study we present should be complemented by other means of investigation that allow the testing of the robustness of our conclusions. Among these figure for example Monte Carlo analysis, various stochastic methodologies, and "investment under uncertainty" approaches. In particular our proposal for an expression reflecting a possible lack of energy security of supply or, alternatively, for a relation simulating the willingness-to-pay for establishing a certain level of long-term energy independency, through Eq. (7), should be further inspected and subjected to much more detailed calibration efforts. Finding data that can confirm (or prove wrong) this equation would be fundamental to take this approach further and to use it (or not) for informing energy policy making.

\section{Acknowledgements}

Johannes Bollen presented the main findings of this report during a workshop dedicated to this subject at the Dutch Ministry of Economic Affairs on 10 January 2008. The feedback from the 
participants, as well valuable suggestions by Rob Aalbers, Ton Manders, and Klaas-Jan Koops are greatly acknowledged. All remaining errors are the sole responsibility of the authors.

\section{References}

Bollen, J.C., 2007. Energy security, air pollution, and climate change: an integrated cost-benefit approach, Netherlands Environmental Assessment Agency, downloadable from 〈www.mnp.nl 〉.

Bollen, J.C., van der Zwaan, B.C.C., Brink, C., Eerens, H., 2009. Local air pollution and global climate change: a combined cost-benefit analysis. Resource and Energy Economics 31, 161-181.

Bosetti, V., Carraro, C., Massetti, E., Sgobbi, A., Tavoni, M., 2009. Optimal energy investment and R\&D strategies to stabilise greenhouse gas atmospheric concentrations. Resource and Energy Economics 31-2, 123-137.

EU, 2007. An energy policy for Europe. Commission of the European Communities, Brussels, 10 January, COM (2007) 1 final.

Gerlagh, R., van der Zwaan, B.C.C., 2004. A sensitivity analysis of timing and costs of greenhouse gas emission reductions under learning effects and niche markets. Climatic Change 65, 39-71.

Gerlagh, R., van der Zwaan, B.C.C., 2002. Long-term substitutability between environmental and man-made goods. Journal of Environmental Economics and Management 44, 329-345.

Heal, G., 2009. The economics of climate change: a post-stern perspective. Climatic Change 96, 275-297.

Holland, M., Hunt, A., Hurley, F., Navrud S., Watkiss, P., 2004. Final Methodology Paper (Volume 1) for the Clean Air for Europe Programme (CAFE), European Commission, DG Environment, AEAT/ED51014/Methodology, Issue 4, Brussels, Belgium.
IEA, 2007. Energy Security and Climate Policy. International Energy Agency, OECD Paris.

Jansen, J.C., Seebregts, A.J., 2010. Long-term energy services security: what is it and how can it be measured and valued. Energy Policy.

Manne, A., Richels, R., 1995. The greenhouse debate: economic efficiency, burden sharing and hedging strategies. Energy Journal 16 (4), 1-37.

Manne, A., Mendelsohn, R., Richels, R., 1995. MERGE: a model for evaluating regional and global effects of GHG reduction policies. Energy Policy 23 (1) 17-34

Manne, A., Richels, R., 2004. MERGE: An Integrated Assessment Model For Global Climate Change. Stanford University.

Nordhaus, W.D., 1977, Economic growth and climate: the case of carbon dioxide. American Economic Review, May 1977.

Nordhaus, W.D., 1993. Rolling the 'DICE': an optimal transition path for controlling greenhouse gases. Resource and Energy Economics 15, 27-50.

Rabl, A., van der Zwaan, B.C.C., 2009. Cost-benefit analysis of climate change dynamics: uncertainties and the value of information. Climatic Change 96 (3) 313-333 (special issue "The economics of climate change: targets and technologies").

Stern, N., et al., 2006. The Economics of Climate Change: The Stern Review. Cambridge University Press, Cambridge, UK.

van der Zwaan, B.C.C., Gerlagh, R., Klaassen, G., Schrattenholzer, L., 2002 Endogenous technological change in climate change modelling. Energy Economics 24, 1 .

Viscusi, W.K., Aldy, J.E., 2003. The value of a statistical life: a critical review of market estimates throughout the world. NBER Working Papers 9487, National Bureau of Economic Research.

Weitzman, M.L., 2001. Gamma discounting. American Economic Review 91 (1), 260-271.

WHO, 2004. The global burden of disease, update 2004, World Health Organisation, Geneva. 